\title{
Interval Kepercayaan untuk Fungsi Nilai Harapan dan Fungsi Ragam Proses Poisson Periodik Majemuk
}

\author{
Auliya Fithry ${ }^{*}$, I Wayan Mangku², I Gusti Putu Purnaba ${ }^{3}$ \\ 1,2,3 Departemen Matematika, Fakultas MIPA, IPB University, Jawa Barat, Indonesia \\ *Corresponding author. Email: auliyafithry@gmail.com
}

\begin{abstract}
ABSTRAK
Proses Poisson periodik majemuk memiliki fungsi nilai harapan dan fungsi ragam. Tujuan dari makalah ini adalah menentukan interval kepercayaan dari fungsi nilai harapan dan fungsi ragam proses Poisson periodik majemuk dengan taraf nyata sebesar $0<\alpha<1$ dan melakukan simulasi untuk mengamati peluang dari parameter-parameter tercakup pada interval kepercayaan. Kami tidak mengasumsikan bentuk parametrik apapun untuk fungsi intensitas kecuali periodik. Kami mempertimbangkan pada kasus yang diamati terdapat hanya satu realisasi dari proses Poisson periodik pada interval yang terbatas. Hasil utama yang diperoleh adalah dua teori mengenai interval kepercayaan untuk parameter-parameter. Hasil simulasi menunjukkan bahwa peluang dari parameter-parameter tercakup pada interval kepercayaan sesuai dengan teori yang diperoleh.
\end{abstract}

Kata Kunci:

Proses Poisson Periodik Majemuk; Fungsi Nilai Harapan; Fungsi Ragam; Interval

Kepercayaan; Fungsi Periodik

ABSTRACT

Compound cyclic Poisson process have the mean and variance functions. The objective of this paper is to construct confidence intervals for respectively the mean and variance functions of a compound cyclic Poisson process with significance level $0<\alpha<1$ and to do a simulation study to observe the probabilities that parameters are contained in the confidence intervals. We do not assume any parametric form for the intensity function except that it is periodic. We consider in the observed there is only one realization of the cyclic Poisson process in a bounded interval. The main results are two theory about confidence intervals for parameters. The simulation shows that the probability values of the observed parameters contained in the confidence intervals are in accordance with the theory.

Keywords:

Compound Cyclic Poisson Process; Mean Function; Variance Function; Confidence Interval; Periodic Function

Format Sitasi:

A. Fithry, I.W. Mangku, and I.G.P. Purnaba, "Interval Kepercayaan untuk Fungsi Nilai Harapan dan Fungsi Ragam Proses Poisson Periodik Majemuk", Jambura J. Math., vol. 4, No. 1, pp. 152 166, 2022, doi: https://doi.org/10.34312/jjom.v4i1.12180

e-ISSN: 2656-1344 (C) 2022 A. Fithry, I.W. Mangku, I.G.P. Purnaba | Under the license CC BY-NC 4.0

Received: 30 November 2021 | Accepted: 1 January 2022 | Online: 3 January 2022 


\section{A. Fithry, et.al}

\section{Pendahuluan}

Kejadian sehari-hari yang bersifat tidak pasti seringkali dapat dijelaskan dengan proses stokastik. Proses stokastik adalah suatu bagian ilmu matematika yang berguna untuk memprediksi kejadian-kejadian di masa mendatang. Proses stokastik dapat diklasifikasikan menjadi proses stokastik waktu diskrit dan proses stokastik waktu kontinu. Salah satu proses stokastik waktu kontinu adalah proses Poisson.

Proses Poisson adalah proses pencacahan di mana banyaknya kejadian dalam suatu interval waktu berdistribusi Poisson. Proses Poisson dibagi menjadi proses Poisson homogen dan takhomogen. Fungsi intensitas proses Poisson homogen merupakan fungsi konstan, sedangkan fungsi intensitas proses Poisson takhomogen bergantung pada waktu.

Salah satu jenis proses Poisson takhomogen adalah proses Poisson periodik, dimana fungsi intensitasnya bergantung pada waktu berupa fungsi periodik. Beberapa penerapan proses Poisson periodik di antaranya pada bidang kesehatan [1], keuangan [2], dan komunikasi [3].

Salah satu bentuk khusus dari proses stokastik adalah proses Poisson majemuk. Proses Poisson majemuk adalah suatu proses penjumlahan barisan peubah acak independent and identically distributed (i.i.d.) dengan suatu sebaran tertentu sebanyak peubah acak Poisson, dan bebas terhadap proses Poisson. Beberapa penggunaan proses Poisson majemuk di antaranya pada bidang fisika yaitu aplikasi pada teori pengembangan longsoran elektron dan distribusi radiasi keadaan tidak stabil di dalam rongga [4], demografi yaitu aplikasi pada pelaporan angka kematian terkait insiden cedera [5], seismologi yaitu aplikasi pada urutan terjadinya gempa susulan di Turki [6], aplikasi pada resiko di bidang keuangan dan asuransi [7], serta aplikasi pada bidang biologi yaitu memodelkan jumlah disentrik dalam dosimetri biologis [8].

Studi tentang proses Poisson majemuk telah banyak dilakukan menggunakan komponen proses Poisson homogen, yaitu proses Poisson yang diasumsikan memiliki fungsi intensitas konstan (tidak bergantung pada waktu). Misalnya, penelitian Kruczek [9] tentang aplikasi proses Poisson majemuk pada alur transportasi truk penambang bijih tembaga. Asumsi tidak dapat digunakan jika pada interval waktu tertentu, suatu kejadian memiliki peluang lebih besar/lebih kecil untuk terjadi dibandingkan pada waktu yang lain [10]. Oleh karena itu, untuk memperluas jangkauan masalah yang dapat dimodelkan, digunakan proses Poisson takhomogen dimana waktu dianggap berpengaruh.

Studi tentang proses Poisson majemuk menggunakan proses Poisson takhomogen sangatlah luas, sehingga studi diawali dengan bentuk khusus, yaitu proses Poisson periodik majemuk. Penelitian tentang proses Poisson majemuk dimulai dengan proses Poisson periodik majemuk. Proses Poisson periodik majemuk merupakan suatu proses Poisson takhomogen dengan fungsi intensitasnya berupa fungsi periodik. Proses Poisson periodik majemuk tidak mengikuti pola sebaran pada umumnya, sehingga yang dapat dihitung hanya berupa nilai harapan dan ragam, dimana keduanya merupakan peubah acak yang nilainya bermacam-macam bergantung pada waktu pengamatan, sehingga disebut fungsi nilai harapan dan fungsi ragam. Penelitian mengenai fungsi nilai harapan dan fungsi ragam proses Poisson periodik majemuk telah dilaporkan oleh Mangku, et.al [11], pendugaan fungsi nilai harapan dan fungsi ragam pada proses Poisson periodik majemuk telah dilaporkan oleh Ruhiyat, et.al [12] 
dan Makhmudah, et.al [13]. Pada waktu pengamatan relatif lama, kedua fungsi tersebut memiliki sebaran asimtotik yaitu mengikuti sebaran tertentu. Penelitian mengenai sebaran asimtotik penduga fungsi nilai harapan dan fungsi ragam pada proses Poisson periodik majemuk telah dilaporkan oleh Adriani [10]. Selanjutnya, untuk memberi infomasi jaminan parameter (fungsi nilai harapan dan fungsi ragam) tercakup dalam suatu interval, perlu ditemukan interval kepercayaan untuk fungsi nilai harapan dan fungsi ragam proses Poisson periodik majemuk [10]. Diharapkan interval kepercayaan dari fungsi nilai harapan dan fungsi ragam tidak tertalu lebar untuk galat $(\alpha)$ berapun, agar dapat dipastikan kedua parameter tersebut tidak menyebar terlalu jauh.

Penelitian mengenai interval kepercayaan fungsi nilai harapan dan fungsi ragam telah dilakukan oleh beberapa peneliti yaitu, selang kepercayaan fungsi nilai harapan dan fungsi ragam proses Poisson majemuk dengan intensitas fungsi pangkat [14], interval kepercayaan fungsi nilai harapan dan fungsi ragam proses poisson majemuk dengan intensitas eksponesial fungsi linear [15]. Adapun pada penelitian ini dilakukan kajian untuk menemukan interval kepercayaan fungsi nilai harapan dan fungsi ragam pada proses poisson majemuk yang fungsi intensitasnya berupa periodik sehingga disebut proses poisson periodik majemuk. Secara spesifik, penelitian ini dilakukan untuk merumuskan interval kepercayaan pada fungsi nilai harapan dan fungsi ragam proses Poisson periodik majemuk, membuktikan kekonvergenan ke $1-\alpha$ peluang parameter tercakup pada interval kepercayaan, serta memeriksa peluang parameter yang diduga terdapat pada interval kepercayaan dengan taraf nyata yang berbeda-beda untuk interval pengamatan terbatas menggunakan simulasi komputer. Penelitian ini diharapkan dapat memberi informasi bagi pengguna model matematika mengenai interval kepercayaan untuk fungsi nilai harapan dan fungsi ragam proses Poisson periodik majemuk.

\section{Metode}

Pada tahap perumuskan interval kepercayaan dari fungsi nilai harapan dan fungsi ragam proses Poisson periodik majemuk diperlukan fungsi nilai harapan dan fungsi ragam, pendugaan dari fungsi nilai harapan dan fungsi ragam, dan sebaram asimtotik dari penduga fungsi nilai harapan dan fungsi ragam. Selain itu, juga diperlukan pemahaman tentang interval kepercayaan. Selanjutnya, dirumuskan interval kepercayaan untuk fungsi nilai harapan dan fungsi ragam proses Poisson periodik majemuk. Teori interval kepercayaan yang ditemukan, selanjutnya diperiksa kekonvergenannya. Proses penelitian dilanjutkan dengan memeriksa peluang parameter yang diduga terdapat pada interval kepercayaan dengan taraf nyata yang berbeda-beda untuk interval pengamatan terbatas menggunakan simulasi komputer.

\subsection{Fungsi Nilai Harapan dan Fungsi Ragam}

Misalkan $\{N(t), t \geq 0\}$ adalah suatu proses Poisson takhomogen dengan fungsi intensitas yang terintegralkan lokal dan tidak diketahui. Fungsi intensitas diasumsikan berupa fungsi periodik dengan periode $(\tau)$ diketahui. Fungsi intensitas tidak diasumsikan memiliki bentuk parametrik apa pun kecuali berupa fungsi periodik, yakni persamaan

$$
\lambda(s)=\lambda(s+k \tau)
$$




\section{A. Fithry, et.al}

berlaku untuk setiap $s \geq 0$ dan semua $k \in N$, dengan $N$ menyatakan himpunan bilangan asli [12]. Kondisi fungsi intensitas ini juga digunakan oleh Helmers [16]. Proses $\{N(t), t \geq 0\}$ dengan fungsi intensitas yang demikian disebut dengan proses Poisson periodik [11].

Selanjutnya, misalkan $\{Y(t), t \geq 0\}$ adalah suatu proses dengan

$$
Y(t)=\sum_{i=1}^{N(t)} X_{i}
$$

di mana $\left\{X_{i}, i \geq 1\right\}$ adalah barisan peubah acak yang independent and identically distributed (i.i.d.), dengan nilai harapan $\mu_{1}<\infty$ dan ragam $\sigma_{1}{ }^{2}<\infty$, serta bersifat bebas terhadap proses $\{N(t), t \geq 0\}$. Proses $\{Y(t), t \geq 0\}$ disebut dengan proses Poisson periodik majemuk. Model pada persamaan (2) adalah perumuman dari proses Poisson majemuk yang mengasumsikan bahwa $\{N(t), t \geq 0\}$ adalah suatu proses Poisson homogen [11].

Misalkan bahwa, untuk suatu $\omega \in \Omega$, realisasi tunggal $N(\omega)$ dari suatu proses Poisson periodik $\{N(t), t \geq 0\}$ terdefinisi di suatu ruang peluang $(\Omega, \mathcal{F}, P)$ dengan fungsi intensitas $\lambda$ yang diamati pada suatu interval terbatas $[0, n]$. Setelah itu, untuk setiap titik data dari realisasi $N(\omega) \cap[0, n]$ yang diamati, misalkan titik data ke-i, $i=1,2, \ldots, N([0, n])$, peubah acak $X_{i}$ yang bersesuaian juga diamati [11]. Karena barisan $X_{i}$ merupakan i.i.d, maka $X_{i}^{2}$ juga merupakan barisan i.i.d dengan nilai harapan $\mu_{2}<\infty$ dan ragam $\operatorname{Var}\left(X_{1}^{2}\right)=\sigma^{2}<\infty$.

Misalkan $E\left(X_{1}\right)=\mu_{1}$, fungsi nilai harapan dari $Y(t)$, dinotasikan dengan $\psi(t)$, diberikan oleh

$$
\psi(t)=E(N(t)) E\left(X_{1}\right)=\Lambda(t) \mu_{1}
$$

dengan

$$
\Lambda(t)=\int_{0}^{t} \lambda(s) d s
$$

Misalkan $E\left(X_{1}^{2}\right)=\mu_{2}$, fungsi ragam dari $Y(t)$, dinotasikan dengan $V(t)$, diberikan oleh

$$
V(t)=E(N(t)) E\left(X_{1}^{2}\right)=\Lambda(t) \mu_{2}
$$

Misalkan

$$
t_{r}=t-\left\lfloor\frac{t}{\tau}\right\rfloor \tau
$$

di mana untuk setiap bilangan real $x,\lfloor x\rfloor$ menyatakan bilangan bulat terbesar yang lebih kecil dari atau sama dengan $x$, dan misalkan pula

$$
k_{t, \tau}=\left\lfloor\frac{t}{\tau}\right\rfloor
$$


Untuk setiap bilangan real $t \geq 0, t$ dapat dinyatakan sebagai

$$
t=k_{t, \tau} \tau+t_{r}
$$

dengan $0 \leq t_{r} \leq \tau$. Misalkan

$$
\theta=\frac{1}{\tau} \int_{0}^{\tau} \lambda(s) d s
$$

yaitu fungsi intensitas global dari proses $\{N(t), t \geq 0\}$, dan diasumsikan bahwa $\theta>0$. Untuk setiap $t \geq 0$ yang diberikan, $\Lambda(t)$ dapat ditulis menjadi

$$
\Lambda(t)=k_{t, \tau} \tau \theta+\Lambda\left(t_{r}\right)
$$

dengan

$$
\Lambda\left(t_{r}\right)=\int_{0}^{t_{r}} \lambda(s) d s
$$

Akhirnya, dengan menyubstitusikan persamaan (10) pada persamaan (3) dan (5), dapat dituliskan menjadi

$$
\begin{aligned}
& \psi(t)=\left(k_{t, \tau} \tau \theta+\Lambda\left(t_{r}\right)\right) \mu_{1}, \\
& V(t)=\left(k_{t, \tau} \tau \theta+\Lambda\left(t_{r}\right)\right) \mu_{2} .
\end{aligned}
$$

Persamaan (12) dan (13) berturut-turut adalah fungsi nilai harapan dan fungsi ragam dari $Y(t)[11,13]$. Terlihat $\theta$ dan $\Lambda\left(t_{r}\right)$ pada persamaan (12) dan (13) tidak saling bebas. Adriani [10] memodifikasi $k_{t, \tau} \tau \theta+\Lambda\left(t_{r}\right)$ dari $\psi(t)$ dan $V(t)$ pada persamaan (12) dan (13). Kuantitas $k_{t, \tau} \tau \theta+\Lambda\left(t_{r}\right)$ dimodifikasi menjadi jumlah terbobot dari dua peubah acak saling bebas, yaitu $\tau \theta=\int_{0}^{\tau} \lambda(s) d s$ ditulis sebagai $\Lambda\left(t_{r}\right)+\Lambda^{c}\left(t_{r}\right)$, dengan $\Lambda\left(t_{r}\right)$ seperti yang didefinisikan sebelumnya dan

$$
\Lambda^{c}\left(t_{r}\right)=\int_{t_{r}}^{\tau} \lambda(s) d s
$$

\subsection{Penduga Fungsi Nilai Harapan dan Fungsi Ragam}

Misalkan

$$
k_{n, \tau}=\left\lfloor\frac{n}{\tau}\right\rfloor .
$$

Penduga bagi fungsi intensitas global $\theta$ telah dikaji oleh Mangku, et.al [11] yaitu

$$
\widehat{\theta}_{n}=\frac{1}{k_{n, \tau} \tau} \sum_{k=0}^{k_{n, \tau}-1} N([k \tau, k \tau+\tau]) .
$$




\section{A. Fithry, et.al}

Selain itu penduga bagi $\Lambda\left(t_{r}\right)$ juga telah dikaji oleh Mangku, et.al [11] yaitu

$$
\widehat{\Lambda}_{n}\left(t_{r}\right)=\frac{1}{k_{n, \tau}} \sum_{k=0}^{k_{n, \tau}-1} N([k \tau, k \tau+\tau])
$$

Penduga dari fungsi nilai harapan $\psi(t)$ dan fungsi ragam $V(t)$ proses Poisson periodik majemuk telah dirumuskan pada $[12,13]$ sebagai berikut,

$$
\begin{aligned}
& \widehat{\psi}_{n}(t)=\left(k_{t, \tau} \tau \widehat{\theta}_{n}+\widehat{\Lambda}_{n}\left(t_{r}\right)\right) \widehat{\mu}_{1, n} \\
& \hat{V}_{n}(t)=\left(k_{t, \tau} \tau \widehat{\theta}_{n}+\widehat{\Lambda}_{n}\left(t_{r}\right)\right) \widehat{\mu}_{2, n}
\end{aligned}
$$

dimana

$$
\begin{aligned}
\widehat{\mu}_{1, n} & =\frac{1}{N([0, n])} \sum_{i=1}^{N([0, n])} X_{i} \\
\widehat{\mu}_{2, n} & =\frac{1}{N([0, n])} \sum_{i=1}^{N([0, n])} X_{i}^{2}
\end{aligned}
$$

dengan $\widehat{\mu}_{1, n}=0$ dan $\widehat{\mu}_{2, n}=0$ pada saat $N([0, n])=0$.

Akibat dari modifikasi pada (12) dan (13), untuk setiap $t>0$, dapat ditulis

$$
\begin{aligned}
& \Lambda(t)=\left(1+k_{t, \tau}\right) \Lambda\left(t_{r}\right)+k_{t, \tau} \Lambda^{c}\left(t_{r}\right), \\
& \widehat{\Lambda}_{n}(t)=\left(1+k_{t, \tau}\right) \widehat{\Lambda}_{n}\left(t_{r}\right)+k_{t, \tau} \widehat{\Lambda}_{n}^{c}\left(t_{r}\right)
\end{aligned}
$$

dimana

$$
\widehat{\Lambda}_{n}^{c}\left(t_{r}\right)=\frac{1}{k_{n, \tau}} \sum_{k=0}^{k_{n, \tau}-1} N\left(\left[k \tau+t_{r}, k \tau+\tau\right]\right) .
$$

Perhatikan juga bahwa $\tau \widehat{\theta}_{n}=\widehat{\Lambda}_{n}\left(t_{r}\right)+\widehat{\Lambda}_{n}^{c}\left(t_{r}\right)$, di mana $\widehat{\Lambda}_{n}\left(t_{r}\right)$ dan $\widehat{\Lambda}_{n}^{c}\left(t_{r}\right)$ saling bebas. Sehingga, masing-masing penduga $\psi(t)$ pada (17) dan $V(t)$ pada (18) dapat dirumuskan menjadi

$$
\begin{aligned}
& \widehat{\psi}_{n}(t)=\left(\left(1+k_{t, \tau}\right) \widehat{\Lambda}_{n}\left(t_{r}\right)+k_{t, \tau} \widehat{\Lambda}_{n}^{c}\left(t_{r}\right)\right) \widehat{\mu}_{1, n} \\
& \hat{V}_{n}(t)=\left(\left(1+k_{t, \tau}\right) \widehat{\Lambda}_{n}\left(t_{r}\right)+k_{t, \tau} \widehat{\Lambda}_{n}^{c}\left(t_{r}\right)\right) \widehat{\mu}_{2, n} .
\end{aligned}
$$

\subsection{Sebaran Asimtotik Penduga Fungsi Nilai Harapan dan Fungsi Ragam}

Menurut Adriani [10], sebaran asimtotik penduga fungsi nilai harapan dan fungsi ragam dari proses Poisson periodik majemuk sebagai berikut

Teorema 1. Misalkan fungsi intensitas $\lambda$ memenuhi persamaan (1) dan terintegralkan lokal. Jika $Y(t)$ memenuhi persamaan (2), maka 


$$
\begin{gathered}
\sqrt{n}\left(\widehat{\psi}_{n}(t)-\psi(t)\right) \stackrel{d}{\rightarrow} \text { Normal }\left(0,\left(1+k_{t, \tau}\right)^{2} \Lambda\left(t_{r}\right) \tau \mu_{1}^{2}+k_{t, \tau}^{2} \Lambda^{c}\left(t_{r}\right) \tau \mu_{1}^{2}+\frac{\sigma_{1}^{2}(\Lambda(t))^{2}}{\theta}\right), \\
\text { untuk } n \rightarrow \infty .
\end{gathered}
$$

Teorema 2. Misalkan fungsi intensitas $\lambda$ memenuhi persamaan (1) dan terintegralkan lokal. Jika $Y(t)$ memenuhi persamaan (2), maka

$$
\begin{gathered}
\sqrt{n}\left(\hat{V}_{n}(t)-V(t)\right) \stackrel{d}{\rightarrow} \text { Normal }\left(0,\left(1+k_{t, \tau}\right)^{2} \Lambda\left(t_{r}\right) \tau \mu_{2}^{2}+k_{t, \tau}{ }^{2} \Lambda^{c}\left(t_{r}\right) \tau \mu_{2}{ }^{2}+\frac{\sigma_{2}^{2}(\Lambda(t))^{2}}{\theta}\right), \\
\text { untuk } n \rightarrow \infty .
\end{gathered}
$$

\subsection{Interval Kepercayaan}

Menurut Hoog, et.al [17], interval kepercayaan adalah penduga interval dengan suatu koefisien kepercayaan. Misalkan $X_{1}, X_{2}, \ldots, X_{n}$ adalah sampel acak dari populasi $X$ yang memiliki fungsi kepekatan peluang $f(x, \theta)$ di mana $\theta$ adalah parameter yang tidak diketahui. Misalkan pula

$$
L=L\left(X_{1}, X_{2}, \ldots, X_{n}\right) \text { dan } U=U\left(X_{1}, X_{2}, \ldots, X_{n}\right)
$$

adalah dua statistik. Penduga interval bagi $\theta$ dengan peluang $(1-\alpha)$ adalah interval statistik $\left[L\left(X_{1}, X_{2}, \ldots, X_{n}\right), U\left(X_{1}, X_{2}, \ldots, X_{n}\right)\right]$ dengan $L \leq U$ sedemikian sehingga

$$
P\left(L\left(X_{1}, X_{2}, \ldots, X_{n}\right) \leq \theta \leq U\left(X_{1}, X_{2}, \ldots, X_{n}\right)\right)=1-\alpha
$$

dengan $0<\alpha<1$. Koefisien kepercayaan adalah peluang parameter $\theta$ berada dalam interval kepercayaan $(L, U)$ yang dinyatakan sebagai

$$
P_{0}=(\theta \epsilon(L, U))=1-\alpha .
$$

\section{Hasil dan Pembahasan}

\subsection{Interval Kepercayaan Fungsi Nilai Harapan dan Fungsi Ragam}

Berdasarkan Teorema 1 dan Teorema 2, dapat dirumuskan interval kepercayaan dengan tingkat kepercayaan $1-\alpha$ bagi $\psi(t)$ dan $V(t)$ seperti berikut.

Akibat 1 (Interval kepercayaan bagi $\psi(t)$ ). Untuk suatu taraf nyata $\alpha$ dengan $0<\alpha<1$, interval kepercayaan bagi $\psi(t)$ diberikan oleh

$$
I_{\psi, n}=\left(\widehat{\psi}_{n}(t) \pm \Phi^{-1}\left(1-\frac{\alpha}{2}\right) \sqrt{\frac{\left(1+k_{t, \tau}\right)^{2} \widehat{\Lambda}_{n}\left(t_{r}\right) \tau \widehat{\mu}_{1, n}^{2}+k_{t, \tau} 2 \widehat{\Lambda}_{n}^{c}\left(t_{r}\right) \tau \widehat{\mu}_{1, n}^{2}+\frac{\widehat{\sigma}_{1, n}^{2}\left(\widehat{\Lambda}_{n}(t)\right)^{2}}{\hat{\theta}_{n}}}{n}}\right)
$$




\section{A. Fithry, et.al}

dengan $\widehat{\sigma}_{1, n}^{2}=\widehat{\mu}_{1, n}^{2}$ dan $\Phi$ menyatakan fungsi sebaran normal baku.

Akibat 2 (Interval kepercayaan bagi $V(t)$ ). Untuk suatu taraf nyata $\alpha$ dengan $0<\alpha<1$, interval kepercayaan bagi $V(t)$ diberikan oleh

$I_{V, n}=\left(\hat{V}_{n}(t) \pm \Phi^{-1}\left(1-\frac{\alpha}{2}\right) \sqrt{\frac{\left(1+k_{t, \tau}\right)^{2} \widehat{\Lambda}_{n}\left(t_{r}\right) \tau \widehat{\mu}_{2, n}^{2}+k_{t, \tau}^{2} \widehat{\Lambda}_{n}^{c}\left(t_{r}\right) \tau \widehat{\mu}_{2, n}^{2}+\frac{\widehat{\sigma}_{2, n}^{2}\left(\widehat{\Lambda}_{n}(t)\right)^{2}}{\widehat{\theta}_{n}}}{n}}\right)$

dengan $\widehat{\sigma}_{2, n}^{2}=\widehat{\mu}_{2, n}^{2}$ dan $\Phi$ menyatakan fungsi sebaran normal baku.

\subsection{Kekonvergenan Interval Kepercayaan Fungsi Nilai Harapan dan Fungsi Ragam}

Teorema 3 (Kekonvergenan peluang $\psi(t) \in I_{\psi, n}$ ). Untuk interval kepercayaan $I_{\psi, n}$ bagi $\psi(t)$ yang diberikan pada Akibat 1, diperoleh

$$
P\left(\psi(t) \in I_{\psi, n}\right) \rightarrow 1-\alpha, \text { untuk } n \rightarrow \infty
$$

Bukti. Dengan menggunakan Akibat 1, ruas kiri Teorema 3 yaitu $P\left(\psi(t) \in I_{\psi, n}\right)$ dapat ditulis

$$
\begin{aligned}
& P\left(\begin{array}{c}
\widehat{\psi}_{n}(t)-\Phi^{-1}\left(1-\frac{\alpha}{2}\right) \sqrt{\frac{\left(1+k_{t, \tau}\right)^{2} \widehat{\Lambda}_{n}\left(t_{r}\right) \tau \hat{\mu}_{1, n}^{2}+k_{t, \tau}{ }^{2} \widehat{\Lambda}_{n}^{c}\left(t_{r}\right) \tau \widehat{\mu}_{1, n}^{2}+\frac{\hat{\sigma}_{1, n}^{2}\left(\widehat{\Lambda}_{n}(t)\right)^{2}}{n}}{n}} \leq \psi(t) \\
\leq \widehat{\psi}_{n}(t)+\Phi^{-1}\left(1-\frac{\alpha}{2}\right) \sqrt{\frac{\left(1+k_{t, \tau}\right)^{2} \widehat{\Lambda}_{n}\left(t_{r}\right) \tau \widehat{\mu}_{1, n}^{2}+k_{t, \tau}{ }^{2} \widehat{\Lambda}_{n}^{c}\left(t_{r}\right) \tau \hat{\mu}_{1, n}^{2}+\frac{\hat{\sigma}_{1, n}^{2}\left(\widehat{\Lambda}_{n}(t)\right)^{2}}{n}}{n}}
\end{array}\right) \\
& =P\left(\begin{array}{c}
-\Phi^{-1}\left(1-\frac{\alpha}{2}\right) \sqrt{\frac{\left(1+k_{t, \tau}\right)^{2} \widehat{\Lambda}_{n}\left(t_{r}\right) \tau \widehat{\mu}_{1, n}^{2}+k_{t, \tau}{ }^{2} \widehat{\Lambda}_{n}^{c}\left(t_{r}\right) \tau \widehat{\mu}_{1, n}^{2}+\frac{\hat{\sigma}_{1, n}^{2}\left(\hat{\Lambda}_{n}(t)\right)^{2}}{\hat{\theta}_{n}}}{n}} \leq-\widehat{\psi}_{n}(t)+\psi(t) \\
\leq \Phi^{-1}\left(1-\frac{\alpha}{2}\right) \sqrt{\frac{\left(1+k_{t, \tau}\right)^{2} \widehat{\Lambda}_{n}\left(t_{r}\right) \tau \widehat{\mu}_{1, n}^{2}+k_{t, \tau}{ }^{2} \widehat{\Lambda}_{n}^{c}\left(t_{r}\right) \tau \hat{\mu}_{1, n}^{2}+\frac{\widehat{\sigma}_{1, n}^{2}\left(\widehat{\Lambda}_{n}(t)\right)^{2}}{\hat{\theta}_{n}}}{n}}
\end{array}\right) \\
& =P\left(\begin{array}{c}
\Phi^{-1}\left(1-\frac{\alpha}{2}\right) \sqrt{\frac{\left(1+k_{t, \tau}\right)^{2} \widehat{\Lambda}_{n}\left(t_{r}\right) \tau \widehat{\mu}_{1, n}^{2}+k_{t, \tau}{ }^{2} \widehat{\Lambda}_{n}^{c}\left(t_{r}\right) \tau \widehat{\mu}_{1, n}^{2}+\frac{\hat{\sigma}_{1, n}^{2}\left(\widehat{\Lambda}_{n}(t)\right)^{2}}{\hat{\theta}_{n}}}{n}} \geq \widehat{\psi}_{n}(t)-\psi(t) \\
\geq-\Phi^{-1}\left(1-\frac{\alpha}{2}\right) \sqrt{\frac{\left(1+k_{t, \tau}\right)^{2} \widehat{\Lambda}_{n}\left(t_{r}\right) \tau \widehat{\mu}_{1, n}^{2}+k_{t, \tau}{ }^{2} \widehat{\Lambda}_{n}^{c}\left(t_{r}\right) \tau \widehat{\mu}_{1, n}^{2}+\frac{\widehat{\sigma}_{1, n}^{2}\left(\widehat{\Lambda}_{n}(t)\right)^{2}}{\hat{\theta}_{n}}}{n}}
\end{array}\right) \\
& =P\left(\begin{array}{c}
-\Phi^{-1}\left(1-\frac{\alpha}{2}\right) \sqrt{\frac{\left(1+k_{t, \tau}\right)^{2} \widehat{\Lambda}_{n}\left(t_{r}\right) \tau \hat{\mu}_{1, n}^{2}+k_{t, \tau}^{2} \widehat{\Lambda}_{n}^{c}\left(t_{r}\right) \tau \hat{\mu}_{1, n}^{2}+\frac{\hat{\sigma}_{1, n}^{2}\left(\hat{\Lambda}_{n}(t)\right)^{2}}{\theta_{n}}}{n}} \leq \widehat{\psi}_{n}(t)-\psi(t) \\
\leq \Phi^{-1}\left(1-\frac{\alpha}{2}\right) \sqrt{\frac{\left(1+k_{t, \tau}\right)^{2} \widehat{\Lambda}_{n}\left(t_{r}\right) \tau \hat{\mu}_{1, n}^{2}+k_{t, \tau}{ }^{2} \widehat{\Lambda}_{n}^{c}\left(t_{r}\right) \tau \hat{\mu}_{1, n}^{2}+\frac{\hat{\sigma}_{1, n}^{2}\left(\widehat{\Lambda}_{n}(t)\right)^{2}}{\hat{\theta}_{n}}}{n}}
\end{array}\right) \\
& =P\left(\begin{array}{c}
-\Phi^{-1}\left(1-\frac{\alpha}{2}\right) \leq \sqrt{\frac{n}{\left(1+k_{t, \tau}\right)^{2} \widehat{\Lambda}_{n}\left(t_{r}\right) \tau \widehat{\mu}_{1, n}^{2}+k_{t, \tau}^{2} \widehat{\Lambda}_{n}^{c}\left(t_{r}\right) \tau \widehat{\mu}_{1, n}^{2}+\frac{\hat{\sigma}_{1, n}^{2}\left(\hat{\Lambda}_{n}(t)\right)^{2}}{\hat{\theta}_{n}}}} \\
\left(\widehat{\psi}_{n}(t)-\psi(t)\right) \leq \Phi^{-1}\left(1-\frac{\alpha}{2}\right)
\end{array}\right) .
\end{aligned}
$$


Interval Kepercayaan untuk Fungsi Nilai Harapan dan Fungsi Ragam Proses Poisson...

Berdasarkan Teorema 1, maka

$\frac{n}{\sqrt{\left(1+k_{t, \tau}\right)^{2} \widehat{\Lambda}_{n}\left(t_{r}\right) \tau \widehat{\mu}_{1, n}^{2}+k_{t, \tau}{ }^{2} \widehat{\Lambda}_{n}^{c}\left(t_{r}\right) \tau \widehat{\mu}_{1, n}^{2}+\frac{\widehat{\sigma}_{1, n}^{2}\left(\widehat{\Lambda}_{n}(t)\right)^{2}}{\widehat{\theta}_{n}}}}\left(\widehat{\psi}_{n}(t)-\psi(t)\right) \stackrel{d}{\rightarrow} \operatorname{Normal}(0,1)$,

untuk $n \rightarrow \infty$.

Akibatnya $P\left(\psi(t) \in I_{\psi, n}\right)$ konvergen ke $P\left(-\Phi^{-1}\left(1-\frac{\alpha}{2}\right) \leq Z \leq \Phi^{-1}\left(1-\frac{\alpha}{2}\right)\right)$ untuk $n \rightarrow \infty$, dengan $Z$ adalah peubah acak normal baku. Selanjutnya diperoleh

$$
\begin{aligned}
P\left(-\Phi^{-1}\left(1-\frac{\alpha}{2}\right) \leq Z \leq \Phi^{-1}\left(1-\frac{\alpha}{2}\right)\right) & =P\left(Z \leq \Phi^{-1}\left(1-\frac{\alpha}{2}\right)\right)-P\left(Z \leq-\Phi^{-1}\left(1-\frac{\alpha}{2}\right)\right) \\
& =P\left(Z \leq \Phi^{-1}\left(1-\frac{\alpha}{2}\right)\right)-P\left(Z \geq \Phi^{-1}\left(1-\frac{\alpha}{2}\right)\right) \\
& =P\left(\Phi^{-1}\left(1-\frac{\alpha}{2}\right)\right)-\left(1-P\left(Z \leq \Phi^{-1}\left(1-\frac{\alpha}{2}\right)\right)\right) \\
& =\Phi\left(\Phi^{-1}\left(1-\frac{\alpha}{2}\right)\right)-\left(1-\Phi\left(\Phi^{-1}\left(1-\frac{\alpha}{2}\right)\right)\right) \\
& =1-\frac{\alpha}{2}-\left(1-\left(1-\frac{\alpha}{2}\right)\right) \\
& =1-\frac{\alpha}{2}-\frac{\alpha}{2} \\
& =1-\alpha
\end{aligned}
$$

Teorema 4 (Kekonvergenan peluang $V(t) \in I_{V, n}$ ). Untuk interval kepercayaan $I_{V, n}$ bagi $V(t)$ yang diberikan pada Akibat 2, diperoleh

$$
P\left(V(t) \in I_{V, n}\right) \rightarrow 1-\alpha, \text { untuk } n \rightarrow \infty .
$$

Bukti. Dengan menggunakan Akibat 2, ruas kiri Teorema 4 yaitu $P\left(V(t) \in I_{V, n}\right)$ dapat ditulis

$$
\begin{aligned}
& P\left(\begin{array}{c}
\hat{V}_{n}(t)-\Phi^{-1}\left(1-\frac{\alpha}{2}\right) \sqrt{\frac{\left(1+k_{t, \tau}\right)^{2} \widehat{\Lambda}_{n}\left(t_{r}\right) \tau \hat{\mu}_{2, n}^{2}+k_{t, \tau}^{2} \widehat{\Lambda}_{n}^{c}\left(t_{r}\right) \tau \hat{\mu}_{2, n}^{2}+\frac{\hat{\sigma}_{2, n}^{2}\left(\widehat{\Lambda}_{n}(t)\right)^{2}}{\hat{\theta}_{n}}}{n}} \leq V(t) \\
\leq \hat{V}_{n}(t)+\Phi^{-1}\left(1-\frac{\alpha}{2}\right) \sqrt{\frac{\left(1+k_{t, \tau}\right)^{2} \widehat{\Lambda}_{n}\left(t_{r}\right) \tau \hat{\mu}_{2, n}^{2}+k_{t, \tau}{ }^{2} \widehat{\Lambda}_{n}^{c}\left(t_{r}\right) \tau \widehat{\mu}_{2, n}^{2}+\frac{\widehat{\sigma}_{2, n}^{2}\left(\widehat{\Lambda}_{n}(t)\right)^{2}}{n}}{\hat{\theta}_{n}}}
\end{array}\right) \\
& =P\left(\begin{array}{c}
-\Phi^{-1}\left(1-\frac{\alpha}{2}\right) \sqrt{\frac{\left(1+k_{t, \tau}\right)^{2} \widehat{\Lambda}_{n}\left(t_{r}\right) \tau \hat{\mu}_{2, n}^{2}+k_{t, \tau}{ }^{2} \widehat{\Lambda}_{n}^{c}\left(t_{r}\right) \tau \hat{\mu}_{2, n}^{2}+\frac{\hat{\sigma}_{2, n}^{2}\left(\widehat{\Lambda}_{n}(t)\right)^{2}}{n}}{\hat{\theta}_{n}}} \leq-\hat{V}_{n}(t)+V(t) \\
\leq \Phi^{-1}\left(1-\frac{\alpha}{2}\right) \sqrt{\frac{\left(1+k_{t, \tau}\right)^{2} \widehat{\Lambda}_{n}\left(t_{r}\right) \tau \hat{\mu}_{2, n}^{2}+k_{t, \tau}{ }^{2} \widehat{\Lambda}_{n}^{c}\left(t_{r}\right) \tau \hat{\mu}_{2, n}^{2}+\frac{\widehat{\sigma}_{2, n}^{2}\left(\hat{\Lambda}_{n}(t)\right)^{2}}{\hat{\theta}_{n}}}{n}}
\end{array}\right) \\
& =P\left(\begin{array}{c}
\Phi^{-1}\left(1-\frac{\alpha}{2}\right) \sqrt{\frac{\left(1+k_{t, \tau}\right)^{2} \widehat{\Lambda}_{n}\left(t_{r}\right) \tau \hat{\mu}_{2, n}^{2}+k_{t, \tau}^{2} \widehat{\Lambda}_{n}^{c}\left(t_{r}\right) \tau \hat{\mu}_{2, n}^{2}+\frac{\hat{\sigma}_{2, n}^{2}\left(\widehat{\Lambda}_{n}(t)\right)^{2}}{\theta_{n}}}{n}} \geq \hat{V}_{n}(t)-V(t) \\
\geq-\Phi^{-1}\left(1-\frac{\alpha}{2}\right) \sqrt{\frac{\left(1+k_{t, \tau}\right)^{2} \widehat{\Lambda}_{n}\left(t_{r}\right) \tau \hat{\mu}_{2, n}^{2}+k_{t, \tau}{ }^{2} \widehat{\Lambda}_{n}^{c}\left(t_{r}\right) \tau \widehat{\tau}_{2, n}^{2} n}{n}}
\end{array}\right)
\end{aligned}
$$




$$
\begin{aligned}
& =P\left(\begin{array}{c}
-\Phi^{-1}\left(1-\frac{\alpha}{2}\right) \sqrt{\frac{\left(1+k_{t, \tau}\right)^{2} \widehat{\Lambda}_{n}\left(t_{r}\right) \tau \hat{\mu}_{2, n}^{2}+k_{t, \tau}{ }^{2} \widehat{\Lambda}_{n}^{c}\left(t_{r}\right) \tau \hat{\mu}_{2, n}^{2}+\frac{\hat{\sigma}_{2, n}^{2}\left(\widehat{\Lambda}_{n}(t)\right)^{2}}{n}}{\hat{\theta}_{n}}} \leq \hat{V}_{n}(t)-V(t) \\
\leq \Phi^{-1}\left(1-\frac{\alpha}{2}\right) \sqrt{\frac{\left(1+k_{t, \tau}\right)^{2} \widehat{\Lambda}_{n}\left(t_{r}\right) \tau \hat{\mu}_{2, n}^{2}+k_{t, \tau}{ }^{2} \widehat{\Lambda}_{n}^{c}\left(t_{r}\right) \tau \hat{\mu}_{2, n}^{2}+\frac{\hat{\sigma}_{2, n}^{2}\left(\widehat{\Lambda}_{n}(t)\right)^{2}}{\hat{\theta}_{n}}}{n}}
\end{array}\right) \\
& =P\left(\begin{array}{c}
-\Phi^{-1}\left(1-\frac{\alpha}{2}\right) \leq \sqrt{\frac{n}{\left(1+k_{t, \tau}\right)^{2} \widehat{\Lambda}_{n}\left(t_{r}\right) \tau \hat{\mu}_{2, n}^{2}+k_{t, \tau}^{2} \widehat{\Lambda}_{n}^{c}\left(t_{r}\right) \tau \hat{\mu}_{2, n}^{2}+\frac{\hat{\sigma}_{2, n}^{2}\left(\hat{\Lambda}_{n}(t)\right)^{2}}{\hat{\theta}_{n}}}} \\
\left(\hat{V}_{n}(t)-V(t)\right) \leq \Phi^{-1}\left(1-\frac{\alpha}{2}\right)
\end{array}\right) .
\end{aligned}
$$

Berdasarkan Teorema 2, maka

$$
\sqrt{\frac{n}{\left(1+k_{t, \tau}\right)^{2} \widehat{\Lambda}_{n}\left(t_{r}\right) \tau \widehat{\mu}_{2, n}^{2}+k_{t, \tau}{ }^{2} \widehat{\Lambda}_{n}^{c}\left(t_{r}\right) \tau \widehat{\mu}_{2, n}^{2}+\frac{\widehat{\sigma}_{2, n}^{2}\left(\widehat{\Lambda}_{n}(t)\right)^{2}}{\widehat{\theta}_{n}}}}\left(\widehat{\psi}_{n}(t)-\psi(t)\right) \stackrel{d}{\rightarrow} \text { Normal }(0,1),
$$

untuk $n \rightarrow \infty$.

$P\left(V(t) \in I_{V, n}\right)$ konvergen ke $P\left(-\Phi^{-1}\left(1-\frac{\alpha}{2}\right) \leq Z \leq \Phi^{-1}\left(1-\frac{\alpha}{2}\right)\right)$ untuk $n \rightarrow \infty$, dengan $Z$ adalah peubah acak normal baku. Selanjutnya diperoleh

$$
\begin{aligned}
P\left(-\Phi^{-1}\left(1-\frac{\alpha}{2}\right) \leq Z \leq \Phi^{-1}\left(1-\frac{\alpha}{2}\right)\right) & =P\left(Z \leq \Phi^{-1}\left(1-\frac{\alpha}{2}\right)\right)-P\left(Z \leq-\Phi^{-1}\left(1-\frac{\alpha}{2}\right)\right) \\
& =P\left(Z \leq \Phi^{-1}\left(1-\frac{\alpha}{2}\right)\right)-P\left(Z \geq \Phi^{-1}\left(1-\frac{\alpha}{2}\right)\right) \\
& =P\left(\Phi^{-1}\left(1-\frac{\alpha}{2}\right)\right)-\left(1-P\left(Z \leq \Phi^{-1}\left(1-\frac{\alpha}{2}\right)\right)\right) \\
& =\Phi\left(\Phi^{-1}\left(1-\frac{\alpha}{2}\right)\right)-\left(1-\Phi\left(\Phi^{-1}\left(1-\frac{\alpha}{2}\right)\right)\right) \\
& =1-\frac{\alpha}{2}-\left(1-\left(1-\frac{\alpha}{2}\right)\right) \\
& =1-\frac{\alpha}{2}-\frac{\alpha}{2} \\
& =1-\alpha
\end{aligned}
$$

\subsection{Simulasi Interval Kepercayaan Fungsi Nilai Harapan dan Fungsi Ragam}

Simulasi dalam penelitian ini menggunakan perangkat lunak $R$. Tujuan simulasi ini adalah untuk memeriksa peluang parameter berada pada interval kepercayaan fungsi nilai harapan $\psi(t)$ dan fungsi ragam $V(t)$ pada interval waktu terbatas menggunakan data bangkitan yang diamati. Hasil interval kepercayaaan yang diperoleh ditampilkan menggunakan perangkat lunak Scilab.

Parameter yang digunakan dalam simulasi adalah

1. $\alpha$ (taraf nyata) $=1 \%, 5 \%$, dan $10 \%$, karena sering digunakan dalam penelitian-penelitian dalam bidang statistika;

2. $\tau$ (periode) yang digunakan yaitu $\tau=1$;

3. Interval pengamatan yang digunakan yaitu $n=20,100$, dan 200;

4. 1000 penduga fungsi nilai harapan $\widehat{\psi}_{n}(t)$ dan 1000 penduga fungsi ragam $\hat{V}_{n}(t)$. 
Langkah-langkah simulasi adalah

1. Membangkitkan realisasi dari proses Poisson periodik dengan rumusan fungsi intensitas

$$
\lambda(s)=5+\left(5 \sin \frac{2 \pi s}{\tau}\right)
$$

2. Membangkitkan nilai-nilai peubah acak $X_{i}, i=1,2,3, \ldots$ yang berpadanan dengan setiap titik data. Data $X_{i}$ dibangkitkan menggunakan sebaran eksponensial dengan parameter $\mu=0,5$, sehingga didapatkan

$$
E(X)=\mu_{1}=\frac{1}{\mu}=2
$$

dan

$$
E\left(X^{2}\right)=\mu_{2}=\frac{2}{\mu^{2}}=8 ;
$$

3. Menggunakan nilai titik $t=2,5$;

4. Menggunakan periode $\tau=1$;

5. Memilih taraf nyata $\alpha$ sebesar $1 \%, 5 \%$, dan $10 \%$;

6. Memilih $n$ sebagai interval waktu pengamatan $[0, n]$;

7. Menentukan interval kepercayaan dari kombinasi titik, $\tau, \alpha$, dan $n$ yang dipilih; dan

8. Memeriksa interval kepercayaan menggunakan plot pada interval waktu pengamatan $[0, n]$.

\subsection{Hasil Simulasi Interval Kepercayaan Fungsi Nilai Harapan dan Fungsi Ragam}

Pada makalah ini disajikan hasil simulasi interval kepercayaan fungsi nilai harapan $\psi(t)$ dan fungsi ragam $V(t)$ untuk $\tau=1, \alpha=1 \%, 5 \%$, dan $10 \%, n=20,100$, dan 200 pada Tabel 1.

Tabel 1. Hasil simulasi interval kepercayaan (IK) fungsi nilai harapan $\psi(t)$ di titik $t=2,5$ dan $\tau=1$ untuk 1000 penduga

\begin{tabular}{ccccccc}
\hline$\alpha$ & $n$ & $\mathrm{~A}$ & $\mathrm{~B}$ & $\mathrm{C}$ & $\mathrm{D}$ & $\mathrm{E}$ \\
\hline $1 \%$ & 20 & 986 & 14 & $98,60 \%$ & $1,40 \%$ & 0,40 \\
\hline & 100 & 988 & 12 & $98,80 \%$ & $1,20 \%$ & 0,20 \\
& 200 & 991 & 9 & $99,10 \%$ & $0,90 \%$ & 0,10 \\
\hline $5 \%$ & 20 & 947 & 53 & $94,70 \%$ & $5,30 \%$ & 0,30 \\
& 100 & 950 & 50 & $95,00 \%$ & $5,00 \%$ & 0 \\
& 200 & 956 & 44 & $95,60 \%$ & $4,40 \%$ & 0,60 \\
\hline $10 \%$ & 20 & 898 & 102 & $89,80 \%$ & $10,20 \%$ & 0,20 \\
& 100 & 900 & 100 & $90,00 \%$ & $10,00 \%$ & 0 \\
& 200 & 904 & 96 & $90,40 \%$ & $9,60 \%$ & 0,40 \\
\hline
\end{tabular}

Keterangan:

$\mathrm{A}$ = Banyaknya IK yang memuat parameter

$\mathrm{B}$ = Banyaknya IK yang tidak memuat parameter

$\mathrm{C}=$ Persentase IK yang memuat parameter

$\mathrm{D}=$ Persentase IK yang tidak memuat parameter

$\mathrm{E}=$ Galat absolut antara $\alpha$ dan persentase IK yang tidak memuat parameter 


\section{A. Fithry, et.al}

Hasil simulasi interval kepercayaan fungsi nilai harapan $\psi(t)$ memperlihatkan persentase interval kepercayaan yang tidak memuat parameter di titik $t=2,5$ dan $\tau=1$ dengan $\alpha=1 \%, 5 \%$, dan $10 \%$ untuk $n=20$, 100, dan 200 yaitu berturut-turut berkisar antara $0,90 \%-1,40 \%, 4,40 \%-5,30 \%$, dan $9,60 \%-10,20 \%$. Galat yang diperoleh antara $\alpha$ dan persentase interval kepercayaan (IK) yang tidak memuat parameter juga cenderung kecil yaitu antara 0 hingga 0,60 . Hal ini menunjukkan bahwa hasil simulasi interval kepercayaan fungsi nilai harapan $\psi(t)$ proses Poisson majemuk dengan taraf nyata yang berbeda-beda telah sesuai dengan teori yang didapatkan. Ilustrasi diberikan pada Gambar 1.

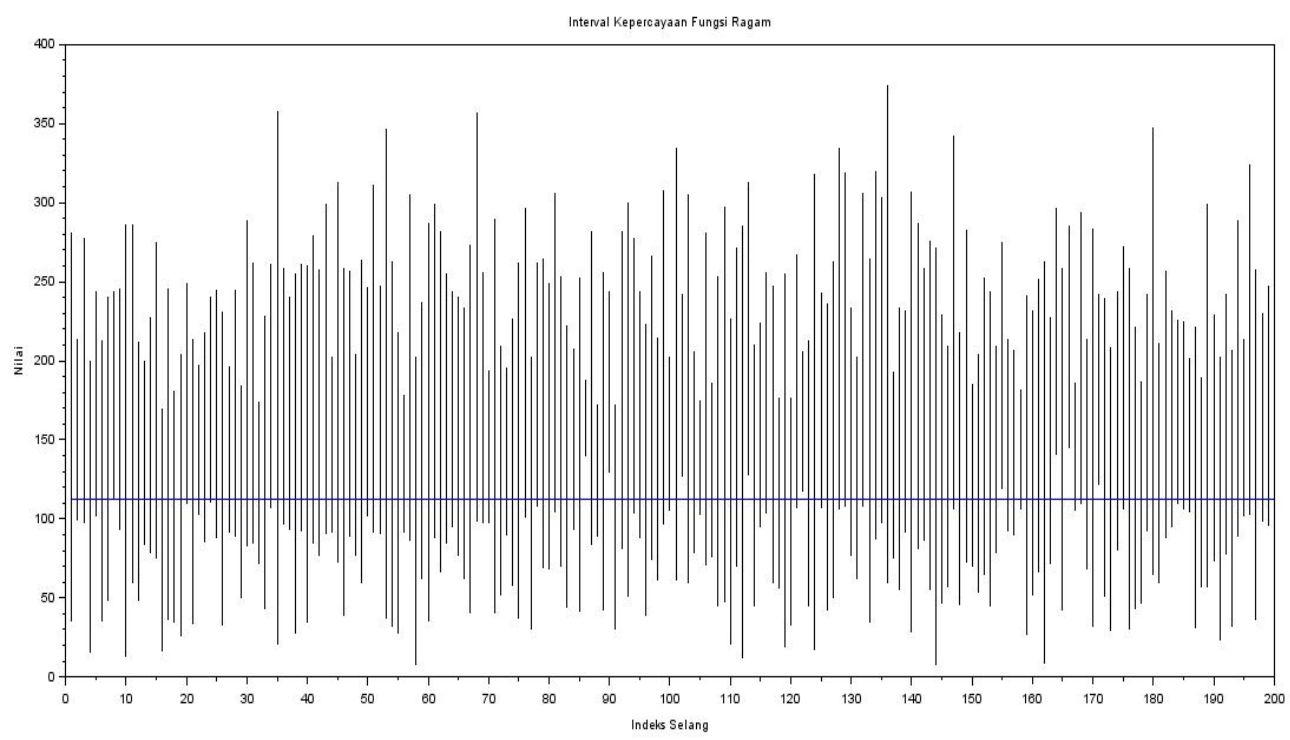

Gambar 1. Interval kepercayaan fungsi nilai harapan $\psi(t)$ di titik $t=2,5, \tau=$ $1, \alpha=1 \%, n=100$

Ilustrasi pada Gambar 1 memperlihatkan sebagian hasil simulasi interval kepercayaan fungsi nilai harapan $\psi(t)$ yaitu pada titik $t=2,5$ dan $\tau=1$ pada 200 penduga pertama dengan taraf nyata $\alpha=1 \%$ dan $n=100$. Dapat dilihat pada gambar di atas terdapat garis horizontal yang menunjukkan nilai dari fungsi nilai harapan $\psi(t)$ yang sebenarnya dan garis vertikal yang menunjukkan interval kepercayaan dari fungsi nilai harapan $\psi(t)$. Jika garis horizontal dan vertikal tidak saling berpotongan menandakan bahwa nilai fungsi nilai harapan $\psi(t)$ tidak berada pada interval tersebut. Pada Gambar 1 , interval kepercayaan fungsi nilai harapan $\psi(t)$ pada titik $t=2,5$ dan, $\tau=1, \alpha=1 \%$, $n=100$ untuk 200 penduga pertama terdapat lima garis yang tidak saling berpotongan yang menandakan nilai dari fungsi nilai harapan $\psi(t)$ sebanyak lima buah tidak berada pada interval tersebut untuk 200 penduga pertama. Sedangkan pada Tabel 1 menyatakan pada titik $t=2,5, \tau=1, \alpha=1 \%, n=100$ terdapat 12 interval kepercayaan yang tidak memuat parameter. Hal ini menunjukkan bahwa tujuh buah dari nilai fungsi nilai harapan $\psi(t)$ yang tidak berada pada interval tersebut terletak pada penduga ke 201 hingga 1000. Selanjutnya, Hasil simulasi interval kepercayaan (IK) fungsi ragam $V(t)$ di titik $t=2,5$ dan $\tau=1$ untuk 1000 penduga disajikan pada Tabel 2. 
Interval Kepercayaan untuk Fungsi Nilai Harapan dan Fungsi Ragam Proses Poisson...

Tabel 2. Hasil simulasi interval kepercayaan (IK) fungsi ragam $V(t)$ di titik $t=$ 2,5 dan $\tau=1$ untuk 1000 penduga

\begin{tabular}{ccccccc}
\hline$\alpha$ & $n$ & $\mathrm{~A}$ & $\mathrm{~B}$ & $\mathrm{C}$ & $\mathrm{D}$ & $\mathrm{E}$ \\
\hline $1 \%$ & 20 & 981 & 19 & $98,10 \%$ & $1,90 \%$ & 0,90 \\
& 100 & 987 & 13 & $98,70 \%$ & $1,30 \%$ & 0,30 \\
& 200 & 990 & 10 & $99,00 \%$ & $1,00 \%$ & 0 \\
\hline $5 \%$ & 20 & 948 & 52 & $94,80 \%$ & $5,20 \%$ & 0,20 \\
& 100 & 951 & 49 & $95,10 \%$ & $4,90 \%$ & 0,10 \\
& 200 & 953 & 47 & $95,30 \%$ & $4,70 \%$ & 0,30 \\
\hline $10 \%$ & 20 & 893 & 107 & $89,30 \%$ & $10,70 \%$ & 0,7 \\
& 100 & 898 & 102 & $89,80 \%$ & $10,20 \%$ & 0,20 \\
& 200 & 900 & 100 & $90,00 \%$ & $10,00 \%$ & 0 \\
\hline
\end{tabular}

Keterangan:

A = Banyaknya IK yang memuat parameter

$\mathrm{B}=$ Banyaknya IK yang tidak memuat parameter

$\mathrm{C}=$ Persentase IK yang memuat parameter

$\mathrm{D}=$ Persentase IK yang tidak memuat parameter

$\mathrm{E}=$ Galat absolut antara $\alpha$ dan persentase IK yang tidak memuat parameter

Hasil simulasi interval kepercayaan fungsi ragam $V(t)$ memperlihatkan persentase interval kepercayaan yang tidak memuat parameter di titik $t=2,5$ dan $\tau=1$ dengan $\alpha=1 \%, 5 \%$, dan $10 \%$ untuk $n=20,100$, dan 200 yaitu berturut-turut berkisar antara $1,00 \%-1,90 \%, 4,70 \%-5,20 \%$, dan $10 \%-10,70 \%$. Galat yang diperoleh antara $\alpha$ dan persentase interval kepercayaan (IK) yang tidak memuat parameter juga cenderung kecil yaitu antara 0 hingga 0,9. Hal ini menunjukkan bahwa hasil simulasi interval kepercayaan fungsi ragam $V(t)$ proses Poisson majemuk dengan taraf nyata yang berbeda-beda telah sesuai dengan teori yang didapatkan. Ilustrasi diberikan pada Gambar 2.

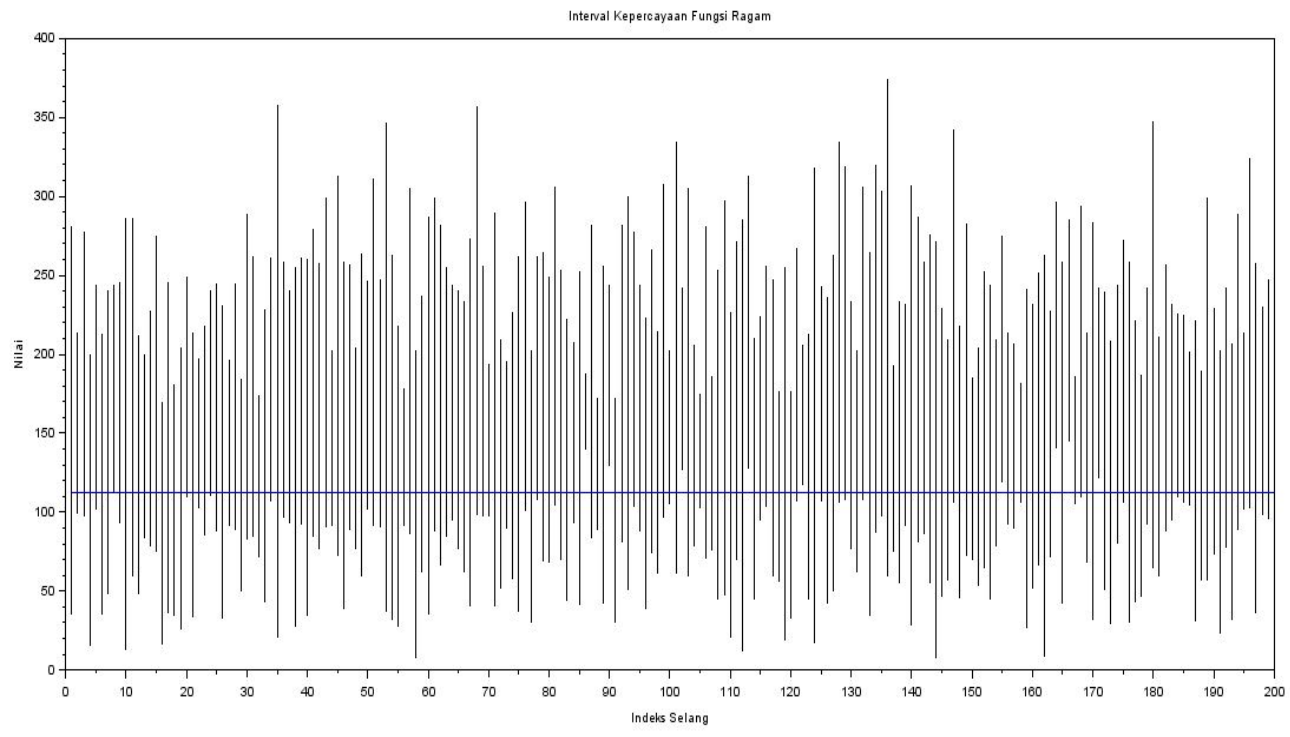

Gambar 2. Interval kepercayaan fungsi ragam $V(t)$ di titik $t=2,5, \tau=1, \alpha=$ $1 \%, n=100$ 


\section{A. Fithry, et.al}

Gambar 2 menunjukkan sebagian simulasi interval kepercayaan fungsi nilai ragam $V(t)$ yaitu pada titik $t=2,5$ dan $\tau=1$ pada 200 penduga pertama dengan taraf nyata $\alpha=1 \%$ dan $n=100$. Arti dari garis horizontal dan garis vertikal adalah sama dengan yang telah dijelaskan untuk parameter fungsi ragam. Jika dilihat pada Gambar 2 interval kepercayaan fungsi nilai ragam $V(t)$ pada titik $t=2,5, \tau=1, \alpha=1 \%, n=100$ untuk 200 penduga pertama terdapat sembilan garis yang tidak saling berpotongan yang menandakan nilai fungsi ragam $V(t)$ sebanyak sembilan buah tidak berada pada interval tersebut untuk 200 penduga pertama. Sedangkan Tabel 2 menyatakan bahwa pada titik $t=2,5, \tau=1, \alpha=1 \%, n=100$ terdapat 13 interval kepercayaan yang tidak memuat parameter. Hal ini menunjukkan bahwa empat buah dari nilai fungsi ragam $V(t)$ yang tidak berada pada interval kepercayaan berdasarkan penduga ke 201 hingga 1000.

Hasil simulasi pada Gambar 1 dan Gambar 2 menunjukkan bahwa peluang fungsi nilai harapan $\psi(t)$ dan fungsi ragam $V(t)$ tercakup pada interval kepercayaan sudah mendekati $1-\alpha$, untuk $\tau=1,5,10, \alpha=1 \%, 5 \%, 10 \%$ untuk interval waktu pengamatan terbatas.

\section{Kesimpulan}

Interval kepercayaan bagi fungsi nilai harapan $\psi(t)$ dan fungsi ragam $V(t)$ proses Poisson periodik majemuk berturut-turut yaitu

$$
\begin{aligned}
& I_{\psi, n}=\left(\widehat{\psi}_{n}(t) \pm \Phi^{-1}\left(1-\frac{\alpha}{2}\right) \sqrt{\frac{\left(1+k_{t, \tau}\right)^{2} \widehat{\Lambda}_{n}\left(t_{r}\right) \tau \widehat{\mu}_{1, n}^{2}+k_{t, \tau}{ }^{2} \widehat{\Lambda}_{n}^{c}\left(t_{r}\right) \tau \widehat{\mu}_{1, n}^{2}+\frac{\widehat{\sigma}_{1, n}^{2}\left(\widehat{\Lambda}_{n}(t)\right)^{2}}{\widehat{\theta}_{n}}}{n}}\right) \\
& I_{V, n}=\left(\hat{V}_{n}(t) \pm \Phi^{-1}\left(1-\frac{\alpha}{2}\right) \sqrt{\frac{\left(1+k_{t, \tau}\right)^{2} \widehat{\Lambda}_{n}\left(t_{r}\right) \tau \widehat{\mu}_{2, n}^{2}+k_{t, \tau}{ }^{2} \widehat{\Lambda}_{n}^{c}\left(t_{r}\right) \tau \widehat{\mu}_{2, n}^{2}+\frac{\widehat{\sigma}_{2, n}^{2}\left(\widehat{\Lambda}_{n}(t)\right)^{2}}{n}}{n}}\right)
\end{aligned}
$$

dimana $\Phi$ menyatakan fungsi sebaran normal baku.

Kekonvergenan peluang interval kepercayaan bagi fungsi nilai harapan $\psi(t)$ dan fungsi ragam $V(t)$ proses Poisson periodik majemuk adalah

$$
\begin{aligned}
& P\left(\psi(t) \in I_{\psi, n}\right) \rightarrow 1-\alpha, \text { untuk } n \rightarrow \infty \\
& P\left(V(t) \in I_{V, n}\right) \rightarrow 1-\alpha, \text { untuk } n \rightarrow \infty .
\end{aligned}
$$

Hasil simulasi menunjukkan bahwa peluang parameter tercakup pada interval kepercayaan sudah mendekati $1-\alpha$ untuk interval pengamatan terbatas dengan taraf nyata yang berbeda-beda telah sesuai dengan teori yang didapatkan.

\section{Referensi}

[1] P. A. W. Lewis, "Recent Results in the Statistical Analysis of Univariate Point Processes," in Stochastic Point Processes: Statistical Analysis, Theory, and Applications, L. PAW, Ed., 1971. 
[2] R. F. Engle, "The Econonometrics of Ultra-High-Frequency Data," Econometrica, vol. 1, no. 68, pp. 1-19, 1996.

[3] E. Belitser, P. Serra, and H. van Zanten, "Rate-optimal Bayesian intensity smoothing for inhomogeneous Poisson processes," Journal of Statistical Planning and Inference, vol. 166, pp. 24-35, nov 2015, doi: http://dx.doi.org/10.1016/j.jspi.2014.03.009.

[4] J. Byrne, "Properties of compound poisson processes with applications in statistical physics," Physica, vol. 41, no. 4, pp. 575-587, mar 1969, doi: http://dx.doi.org/10.1016/ 0031-8914(69)90096-2.

[5] S. R. Kegler, "Applying the compound Poisson process model to the reporting of injury-related mortality rates," Epidemiologic Perspectives and Innovations, vol. 4, no. 1, pp. 1-9, 2007, doi: http://dx.doi.org/10.1186/1742-5573-4-1.

[6] G. Özel and C. İnal, "The probability function of the compound Poisson process and an application to aftershock sequence in Turkey," Environmetrics, vol. 19, no. 1, pp. 79-85, feb 2008, doi: http://dx.doi.org/10.1002/env.857.

[7] V. E. Bening and V. Y. Korolev, Generalized Poisson Models and their Applications in Insurance and Finance. Boston: VSP Internasional Science, 2002.

[8] P. Puig and J. F. Barquinero, "An application of compound Poisson modelling to biological dosimetry," Proceedings of the Royal Society A: Mathematical, Physical and Engineering Sciences, vol. 467, no. 2127, pp. 897-910, mar 2011, doi: http://dx.doi.org/10.1098/rspa.2010.0384.

[9] P. Kruczek, M. Polak, A. Wyłomańska, W. Kawalec, and R. Zimroz, "Application of compound Poisson process for modelling of ore flow in a belt conveyor system with cyclic loading," International Journal of Mining, Reclamation and Environment, vol. 32, no. 6, pp. 376-391, aug 2018, doi: http://dx.doi.org/10.1080/17480930.2017.1388335.

[10] I. R. Adriani, "Sebaran Asimtotik Penduga Fungsi Nilai Harapan dan Fungsi Ragam pada Proses Poisson Periodik Majemuk," IPB University, IPB University, Tech. Rep., 2019.

[11] I. W. Mangku, R. Ruhiyat, and I. G. P. Purnaba, "Statistical Properties of An Estimator for the Mean Function of A Compound Cyclic Poisson Process," Far East J. Math. Sci., vol. 82, no. 2, pp. 227-237, 2014.

[12] R. Ruhiyat, I. W. Mangku, and I. G. P. Purnaba, "Consistent Estimation of the Mean Function of A Compound Cyclic Poisson Process," Far East J. Math. Sci., vol. 77, no. 2, pp. 183-194, 2013.

[13] F. I. Makhmudah, I. W. Mangku, and H. Sumarno, "Estimating the Variance Function of A Compound Cyclic Poisson Process," Far East Journal of Mathematical Sciences (FJMS), vol. 100, no. 6, pp. 911-922, sep 2016, doi: http://dx.doi.org/10.17654/MS100060911.

[14] A. Fajri, "Selang kepercayaan fungsi nilai harapan dan fungsi ragam proses poisson majemuk dengan intensitas fungsi pangkat," IPB University, Tech. Rep., 2017.

[15] S. Utami, "Interval Kepercayaan Fungsi Nilai Harapan dan Fungsi Ragam Proses Poisson Majemuk dengan Intensitas Eksponesial Fungsi Linear," IPB University, Tech. Rep., 2018.

[16] R. Helmers, I. Wayan Mangku, and R. Zitikis, "Consistent estimation of the intensity function of a cyclic Poisson process," Journal of Multivariate Analysis, vol. 84, no. 1, pp. 19-39, jan 2003, doi: http://dx.doi.org/10.1016/S0047-259X(02)00008-8.

[17] R. V. Hoog, J. W. Mckean, and A. T. Craig, Introduction to Mathematical Statistics, 8th ed. New York: Pearson Education Inc., 2019.

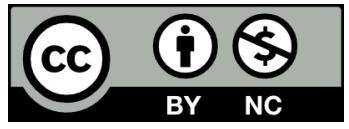

This article is an open-access article distributed under the terms and conditions of the Creative Commons Attribution-NonCommercial 4.0 International License. Editorial of JJoM: Department of Mathematics, Universitas Negeri Gorontalo, Jln. Prof. Dr. Ing. B.J. Habibie, Moutong, Tilongkabila, Kabupaten Bone Bolango, Provinsi Gorontalo 96119, Indonesia. 